\title{
A filosofia crítica de Foucault: uma recusa do transcendental?
}

\author{
Foucault's critical philosophy: a refusal of the transcendental?
}

Carolina de Souza Noto

carunoto@hotmail.com

(Universidade de São Paulo, São Paulo, Brasil)

\begin{abstract}
Resumo: 0 presente artigo pretende defender que, em Foucault, há uma filosofia crítica que não pode ser compreendida exatamente nos mesmos termos que a filosofia crítica de Kant. Apesar de a filosofia crítica de Foucault investigar as condições de possibilidades de um saber, tais condições não são condições transcendentais de possibilidade, assim como em Kant. 0 interesse crítico de Foucault não é pelas condições subjetivas universais que possibilitam, em geral, o conhecimento verdadeiro, mas pelas condições singulares ou históricas que fazem com que, numa determinada época, um campo de saber possa existir. Nesse sentido, pode-se mesmo dizer que a filosofia crítica de Foucault consiste numa inversão da filosofia crítica de Kant.
\end{abstract}

\begin{abstract}
The present article aims to maintain that, in Foucault, there is a critical philosophy that cannot be understood exactly on the same terms as Kant's critical philosophy. Even though Foucault's critical philosophy investigates the conditions in which knowledge is possible, such conditions are not transcendental possibility conditions, as they are in Kant. Foucault's critical interest is not on the universal subjective conditions that, generally speaking, make true knowledge possible, but on the singular conditions that make it so that, at a specific period, a field of knowledge can exist. In this sense, we can say that the Foucault's critical philosophy is a reversal of the Kant's critical philosophy.
\end{abstract}

Palavras-chave: filosofia crítica; Keywords: critical philosophy; transcendental; Foucault; Kant. transcendental; Foucault; Kant.

O presente artigo tem como ponto de partida uma pergunta que me foi colocada na defesa de minha tese de doutorado, defendida em de 2014, na Faculdade de Filosofia, Letras e Ciências Humanas (FFLCH) da Universidade de São Paulo (USP). A pergunta punha em questão o próprio titulo do trabalho, a saber: "A recusa do transcendental: um estudo sobre a filosofia crítica de Foucault”. O problema levandado pelo arguidor $^{1}$ era o de saber se, de fato, em Foucault, trata-se de uma "recusa do transcendental" e, se sim, por que, afinal, continuar falando em filosofia crítica se esta não leva em conta a problemática transcendental. Apesar de considerar que a

10 arguidor em questão foi o Prof. Dr. Márcio Suzuki. 
resposta a esta questão poderia ser encontrada na própria tese, gostaria de retomar aqui, de maneira mais resumida, alguns argumentos a favor da ideia de que, em Foucault, existe uma filosofia crítica que não deve ser compreendida exatamente nos mesmos termos em que nosso autor define a crítica kantiana e que se, em Foucault, há uma discussão acerca das condições de possibilidade de um saber, tais condições não devem ser entendidas no sentido que nosso autor dá ao transcendental kantiano.

Grosso modo, podemos dizer que a relação de Foucault com Kant é marcada por dois momentos distintos. Um primeiro momento que gira em torno do problema antropológico anunciado em sua tese complementar "Introdução à Antropologia de um ponto de vista pragmático", de 1961, e desenvolvido em As palavras e as coisas, de 1966; e um segundo momento que retoma a questão da atualidade no texto “Resposta à pergunta: O que é Esclarecimento?”, e isso a partir do final da década de 1970.

Em geral, interpreta-se da seguinte maneira a leitura foucaultiana de Kant: em seu período arqueológico, isto é, no primeiro momento, da década de 1960, Foucault teria encontrado em Kant uma possível origem para o nascimento das ciências humanas; em Kant estaria não só a origem do questionamento transcendental acerca das condições de possibilidade da experiência, mas também o anúncio do problema da confusão entre empírico e transcendental que seria retomado pelas ciências humanas em geral, assim como pela filosofia, principalmente em sua vertente fenomenológica, que procuram conhecer o homem tal como é, de fato, no mundo. Por outro lado, em seu período genealógico, das décadas de 1970 e 1980, Foucault teria visto em Kant um modelo teórico interessante, e não problemático, para realizar uma ontologia do presente, que consistiria num questionamento filosófico acerca daquilo que somos nos dias de hoje. No primeiro momento, Kant teria para Foucault uma função mais estratégica do que teórica; a partir de uma análise da antropologia pragmática de Kant, Foucault poderia estrategicamente sustentar suas teses arqueológicas sobre o nascimento das ciências humanas ${ }^{2}$. No segundo momento, por outro lado, o interesse de Foucault por Kant seria, aí sim, mais teórico, visto que nosso autor deixa claro que vê no Kant de “O que é o Esclarecimento?" um paradigma de reflexão no qual teoricamente se inspira e do qual se diz herdeiro.

No meu entender, contudo, não é somente o Kant do famoso opúsculo que teve interesse teórico para Foucault. Acredito, pois, que já em sua leitura da Antropologia de um ponto de vista pragmático, Foucault encontrara soluções teóricas importantes a serem seguidas por ele em suas investigações arqueológicas e genealógicas sobre o homem no mundo. Mas por que "soluções teóricas”? Quem diz "solução teórica"

2 Essa é, pois, a interpretação de Béatrice Han, que afirma, por exemplo: "a importância da interpretação de Kant por Foucault é mais estratégica do que teórica" (HAN, B. L'ontologie manqué de Michel Foucault. Grenoble: Millon, 1998, p.58). 
deve supor a existência de um "problema teórico" que deve ser solucionado. Que "problema teórico" seria esse a que Foucault teria encontrado uma solução e de que maneira a antropologia pragmática de Kant lhe teria ajudado, ao menos em parte, a resolvê-lo?

Diria que o grande problema filosófico, pelo menos o mais geral, enfrentado por Foucault ao longo de todo seu percurso filosófico fora o de construir um tipo de reflexão sobre o homem que não caísse nas contradições a que chegam as ciências humanas ou a fenomenologia. Contradições essas oriundas de uma confusão entre aquilo que, no homem, pode ser conhecido empiricamente (aquilo que nele é determinado por sua inserção num mundo mais antigo do que ele) e aquilo que só é possível de ser conhecido transcendentalmente (ou seja, aquilo que nele é determinante de maneira universal e, portanto, a priori $)^{3}$. E se, por um lado, Foucault localiza em Kant o possível nascimento dessas confusões, gostaria de mostrar que nosso autor encontra na Antropologia de um ponto de vista pragmático, de Kant, uma via possível para conhecer o homem tal como ele está, de fato, constituido no mundo sem que esse conhecimento tenha validade de um conhecimento transcendental acerca das condições constituintes do homem. No meu entender, o grande interesse teórico de Foucault pela antropologia pragmática de Kant fora o de ter encontrado aí uma "boa antropologia"; uma antropologia que é capaz de ter um conhecimento do homem no mundo de maneira não contraditória. E a condição para essa "boa antropologia”, que será seguida por Foucault, como veremos, será a de ser uma investigação empírica sobre o homem no mundo que não se configura como uma investigação transcendental sobre ele.

Esse artigo está dividido em três partes. Na primeira delas, retomarei aquilo que, aos olhos de Foucault, é o problema teórico enfrentado pelas ciências humanas assim como pela fenomenologia e de que modo esse problema se liga arqueologicamente a Kant. Num segundo momento, procurarei mostrar porque a Antropologia de um ponto de vista pragmático é, para Foucault, uma "boa antropologia". Por fim, no terceiro momento, falarei sobre as apropriações que Foucault parece fazer da antropologia pragmática de Kant, chamando atenção para o fato de que se em Foucault existe uma filosofia crítica que se pergunta pelas condições de possibilidade do homem no mundo, essa filosofia não pode ser compreendida nos mesmos termos que a filosofia transcendental kantiana.

\footnotetext{
3 Em As palavras e as coisas, por exemplo, ao comentar a tarefa da Crítica da Razão Pura, Foucault afirma que tratava-se ali de encontrar as condições universais de possibilidade de toda e qualquer representação e que, para serem universais, tais condições deveriam ser a priori e fundarem-se além de toda experiência (Cf. As palavras e as coisas. Tradução de Salma Tannus Muchail. São Paulo: Martins Fontes, 2002, p.333).
} 


\section{O problema teórico das ciências humanas e da fenomenologia: o homem no mundo}

Em um de seus livros mais importantes, As palavras e as coisas (1966), Foucault defende a tese de que na modernidade não está mais em questão aos saberes em geral descrever como se dá a relação entre uma representação e outra, entre uma ideia e outra, mas se perguntar como a representação em si é possível. Para o filósofo, principalmente no campo da reflexão filosófica, tornam-se centrais as questões relativas às condições de possibilidades a priori da experiência, ou seja, aquilo que está aquém ou além das representações, mas que ao mesmo tempo é aquilo mesmo que as possibilita.

Na filosofia, Kant seria o marco dessa mudança de episteme. É, por exemplo, da seguinte maneira que Foucault marca a diferença entre Kant e o pensamento clássico de Descartes ou ainda de Condillac e Destutt de Tracy:

Em face da Ideologia, a critica kantiana marca, em contrapartida, o limiar de nossa modernidade; interroga a representação, não segundo o movimento indefinido que vai do elemento simples a todas as suas combinações possíveis, mas a partir de seus limites de direito. Sanciona assim, pela primeira vez, este acontecimento da cultura europeia que é contemporâneo do fim do século XVIII: a retirada do saber e do pensamento para fora do espaço da representação. Este é então posto em questão no seu fundamento, na sua origem e nos seus limites: por isso mesmo, o campo ilimitado da representação, que o pensamento clássico instaura, que a Ideologia quisera percorrer num passo a passo discursivo e científico, aparece como uma metafísica. ${ }^{4}$

De acordo com Foucault, a distinção entre o “Eu penso" e o “Eu sou” estabelecida por Kant seria paradigmática para compreender o que separa o pensamento clássico do moderno. O "Eu penso" ainda diria respeito ao cogito cartesiano povoado de representações; o "Eu sou”, por outro lado, seria o objeto da investigação crítica e transcendental que se pergunta "o que sou eu que sou capaz de ter representações e de pensar". O aparecimento do sujeito transcendental kantiano é, portanto, a marca do nascimento de nossa modernidade; um sujeito "que jamais é dado à experiência (pois não é empírico), mas que é finito (pois não tem intuição intelectual)" e que funciona como "fundamento de uma síntese possível entre as representações" ou como aquilo que garante "as condições formais da experiência em geral" 5.

Para Foucault, contudo, o sujeito transcendental kantiano ainda não seria exatamente aquilo que constitui o que ele chama de homem e que seria o objeto problemático das ciências humanas e de certo tipo de reflexão filosófica chamada, pelo autor, de analítica da finitude. Em Kant, o sujeito transcendental é ainda um sujeito puro ${ }^{6}$. O homem, entretanto, será uma figura mista, um duplo ontológico,

4 FOUCAULT, M. As palavras e as coisas, p.334.

5 Idem, p.429.

6 Sobre a compreensão de Foucault acerca do sujeito transcendental kantiano como um sujeito 
e não somente lógico, de transcendental e de empírico, um ser ambíguo pois ontologicamente constituinte e constituído, determinante e determinado.

Segundo Foucault, são todas estas reflexões que procuraram dar estatuto ontológico à condição dupla do homem que caem naquilo que o filósofo chama de “ilusão antropológica”. Ilusão esta que se dá em função de uma torção do sentido da ilusão transcendental e que acaba sendo uma espécie de repetição da "ilusão transcendental" denunciada por Kant? ${ }^{7}$.

De acordo com Foucault, a ilusão transcendental analisada por Kant na Crítica da Razão Pura foi questionada pelas analíticas da finitude num nível ainda mais radical e fundamental. A ilusão antropológica, diz, "ao invés de ser definida pelo movimento que a criticava no interior de uma reflexão sobre o conhecimento [como a ilusão

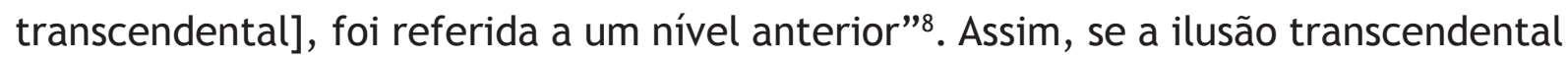
consistia numa transgressão dos limites do conhecimento, numa tendência natural da razão de encontrar para suas ideias uma correspondência na intuição sensível, a ilusão antropológica, dirá Foucault, "reside numa regressão reflexiva que deve dar conta dessa transgressão", que deve dar conta de conhecer o ser mesmo do homem como um ser finito e limitado, mas capaz de ultrapassar e superar sua alienação constitutiva por meio do conhecimento de si. Desde então, conclui o filósofo, "o problema da finitude passou de uma interrogação sobre o limite e a transgressão para uma interrogação sobre o retorno a si" ". A partir de então, a verdade mais profunda do homem será aquela que o designa como um ser constitutivamente alienado de si mesmo, mas que não pode deixar de percorrer o caminho que vai do Outro de si ao si Mesmo, que vai do desconhecido ao conhecimento de si mesmo como ser naturalmente finito, opaco e sombrio. Para Foucault, portanto, a passagem de Kant às aporias das filosofias sobre o homem caracterizar-se-ia pela passagem de uma reflexão epistemológica sobre os limites e as transgressões no domínio do conhecimento, para uma reflexão ontológica acerca da natureza da natureza finita, mas superadora, do homem ${ }^{10}$. Confirma Foucault:

puro, como subjetividade soberana e fundadora ou como atividade constituinte Cf. FOUCAULT, M. "Réponse à une question". In: Dits et écrits vol. I. Paris: Gallimard, 2001, p.758 e As palavras e as coisas, p.225.

7 Foucault, na introdução à Antropologia de um ponto de vista pragmático, afirma que a confusão operada pelas reflexões sobre o homem entre empírico e transcendental nasce dessa primeira confusão que Kant apontara na Crítica da Razão Pura. Confirma nosso autor: “de fato, uma deriva historicamente da outra, ou melhor, é por uma mudança de sentido da crítica kantiana à ilusão transcendental que a ilusão antropológica pode nascer” (FOUCAULT, M. “Introduction à l'Anthropologie". In: KANT, I. Anthropologie d'un point de vue pragmatique. Paris: Vrin, 2008, p.77).

8 FOUCAULT, M. “Introduction à l'Anthropologie”, p.77.

9 Idem, ibidem.

10 Essa interpretação acerca da fortuna kantiana Foucault parece compartilhar tanto com Jean Hyppolite, quanto com Jules Vuillemin. Cf., por exemplo, Hyppolite apud Vuillemin: “A crítica que Kant faz da ontologia clássica está destinada a preparar uma nova ontologia, aquela em que 
O caráter necessário da aparência transcendental foi cada vez mais interpretado não como uma estrutura da verdade, do fenômeno e da experiência, mas como um dos estigmas concretos da finitude. 0 que Kant designou na Crítica, de um modo bastante ambíguo, como "natural", foi esquecido como forma fundamental da relação ao objeto e recuperado como "natureza" da natureza humana (...) Esta ilusão definida agora como finitude tornava-se por excelência o refúgio da verdade: aquilo no qual ela se esconde e aquilo no que sempre se pode recuperá-la ${ }^{11}$.

Mas qual afinal seria o problema de uma reflexão ontológica acerca da natureza finita do homem? O problema, segundo Foucault, não está simplesmente em operar uma torção no sentido que Kant dera à "ilusão transcendental", mas no fato da “ilusão antropológica” consistir numa repetição dessa primeira ilusão.

Como se sabe, o grande problema da “ilusão transcendental" está em conferir estatuto empírico a algo que só poderia ter estatuto transcendental, realidade objetiva a algo que só possuiria realidade subjetiva ${ }^{12}$. Voltemos, por exemplo, ao primeiro tipo de raciocínio dialético descrito por Kant na "Dialética Transcendental", os paralogismos da razão pura. Trata-se do caso em que a razão produz a ideia de um sujeito como unidade absoluta do Eu que percebe, sente e pensa; ideia essa que não corresponde a nenhum objeto que pode ser legitimamente conhecido, mas apenas pensado enquanto conceito problemático. Para os metafísicos, esse Eu anterior a qualquer ato de perceber, sentir, pensar ou conhecer e que funcionaria como polo unificador dessas diversas atividades seria o eu pensante enquanto alma. Segundo Kant, esta psicologia racional do eu pensante opera um raciocínio falso e acaba caindo no que o filósofo chama de "ilusão transcendental" pois procurara dar à unidade do eu e do pensamento, que é simplesmente uma unidade transcendental e subjetiva, uma unidade objetiva. Ou seja, pretenderam conhecer por meio de uma intuição aquilo que só poderia ser pensado especultaivamente por meio da razão pura ${ }^{13}$.

Ora, nas metafísicas sobre o homem ou nas antropologias que se desenvolvem depois de Kant é esse mesmo tipo de confusão entre empírico e transcendental que, segundo Foucault, se repete. Ao pretender conhecer a natureza da natureza finita do homem, as analíticas da finitude partem de um conhecimento empírico do homem

o ser é o sujeito que se coloca a si mesmo, um ato e não um substrato inerte. O ser é liberdade" (VUILLEMIN, J. L'Héritage kantien et la révolution copernicienne: Fichte - Cohen - Heidegger. Paris: PUF, 1954, p.2).

11 Foucault, “Introduction à l'Anthropologie”, p.77. Com efeito, Otfried Höffe, em seu livro sobre Kant, comenta a dialética da razão nos temos de finitude: "a dialética passa a ser uma característica constitutiva da razão humana, o sinal de sua finitude” (HÖFFE, O. Immanuel Kant. Tradução de Christian Viktor Hamm e Valerio Rohden. São Paulo: Martins Fontes, 2005, p.19).

12 Cf. KANT, I. Crítica da Razão Pura A 339/B397. Que Kant tenha estabelecido como domínio do transcendental o que é de ordem meramente especulativa é o que ele parece deixar claro na Crítica da Razão Pura ao definir a filosofia transcendental como "uma filosofia da razão pura meramente especulativa”, que não se refere a fontes empíricas do conhecimento (KANT, I. Crítica da Razão Pura A 15/B 29).

13 Cf. KANT, I. Crítica da Razão Pura, A 348/B 406. 
(de uma verdade de fato) mas querem dar a esse conhecimento empírico o estatuto de um conhecimento transcendental (uma verdade de razão); como se a finitude concreta do homem, conhecida pela experiência sensível, fosse já sua finitude fundamental e radical; como se as determinações que conhecemos empiricamente no homem fossem já aquilo que nele é determinante transcendentalmente e que só pode ser pensado especulativamente ou conhecido de modo problemático. De acordo com Lebrun, é principalmente Merleau-Ponty que Foucault tem em mente quando fala da confusão entre o empírico e o transcendental. Afinal, é o retorno ao vivido que nos coloca diante de uma situação ambígua e aporética que fica num vai e vem sem fim entre a descrição empírica e a fundamentação transcendental ${ }^{14}$.

Aos olhos de Foucault, o problema das analíticas da finitude foi o de não terem respeitado a distinção metodológica, indicada por Kant, entre o que pode ser conhecido empiricamente pela experiência (o homem como ser concretamente finito, constituído e determinado) e o que só pode ser pensado transcendentalmente (aquilo que no homem seria sua finitude fundalmental, constituinte e determinante). 0 fato de as analíticas da finitude nos apresentarem o homem como uma figura ambígua e ontologicamente dupla em relação ao qual é impossível decidir se é constituinte ou constituído, determinante ou determinado, se deve justamente à não observância do ensinamento kantiano. Para Foucault, a finitude humana como condição constitutiva e determinante do homem é algo que só pode ser pensado transcendentalmente, mas não conhecido empiricamente por meio da experiência sensível; o conhecimento empírico do homem só nos faz conhecê-lo como um ser constituído e determinado e nunca nos dá o seu ser constituinte e determinante. Desse modo, se Foucault afirma que as analíticas da finitude começaram a partir de Kant, é importante levar a sério a ressalva de que elas não começaram com ele, pois se elas operam a confusão entre empírico e transcendental, Kant, porém, mostrara essa distinção ${ }^{15}$.

\section{A Antropologia de um ponto de vista pragmático como uma "boa antropologia"}

Que Kant tenha mantido a distinção entre empírico e transcendental na Crítica da Razão Pura parece inquestionável; sabemos, pois, que este é desde o início o seu propósito e sua advertência, principalmente na "Dialética Transcendental". Porém, chegar às mesmas conclusões no que se refere à Antropologia de um ponto de vista pragmático parece ser mais delicado. Pois, afinal, como seria possível manter aí a distinção entre o empírico e o transcendental se a antropologia pragmática, como diz o próprio Foucault, não deixa de ser uma espécie de repetição da Crítica? Como, então, conciliar a tese de que na antropologia pragmática não há confusão entre

14 LEBRUN, G. "Transgredir a finitude”. In: RIBEIRO, R. (org.). Recordar Foucault. São Paulo: Brasiliense, 1985, pp.12-3.

15 FOUCAULT, M. As palavras e as coisas, p.471. 
empírico e transcendental se na Antropologia de um ponto de vista pragmático, conforme Foucault afirma, transcendental e empírico são dados numa continuidade indivisível? ${ }^{16}$

No entender de Béatrice Han, a tese complementar de Foucault sobre a Antropologia de um ponto de vista pragmático teve como objetivo mostrar que, se por um lado Kant manteve a distinção entre empírico e transcendental na Crítica, na Antropologia ele acabou confundindo as duas instâncias. Nesse sentido, já em Kant poderíamos encontrar a "ilusão antropológica" que estaria presente nas futuras reflexões sobre o homem ${ }^{17}$.

A meu ver, contudo, a tese complementar de Foucault sobre a antropologia pragmática de Kant mostra precisamente o contrário: mostra em que medida ela é um tipo de investigação empírica que mantém relações com o questionamento transcendental, sem, porém, configurar-se como uma reflexão que confunde um e outro domínio; mostra que a antropologia pragmática de Kant é uma "boa" antropologia que não dorme no sono antropológico e que não pode ser confundida com as antropologias subsequentes. Como veremos, isso se deve ao fato de a antropologia pragmática estar situada no domínio das questões relativas à maneira como o homem habita o mundo, e não no domínio dos problemas referentes à fundamentação da finitude do homem; sua preocupação não será, pois, responder à pergunta "O que é o Homem?" (a famosa quarta questão anunciada por Kant na Lógica ${ }^{18}$ ), mas pensar o homem enquanto cidadão do mundo, pensar como o homem habita um mundo que é mais antigo do que ele e como ele faz uso desse mundo. Insiste Foucault: "a Antropologia tal como a conhecemos em nenhum momento se dá como resposta à quarta questão"19.

Segundo Foucault, o espaço da antropologia de Kant não é nem aquele de uma investigação puramente transcendental, como é o caso de uma investigação crítica, nem aquele de uma investigação estritamente empírica, como seria o caso de uma psicologia empírica ou de uma fisiologia. Diz o filósofo acerca do domínio da antropologia pragmática:

E o domínio da antropologia, longe de ser o do mecanismo da natureza e das determinações extrínsecas (ela seria então uma "fisiologia") é inteiramente habitado pela presença surda, solta e por vezes desviada de uma liberdade que se exerce no

16 "O que a Crítica distinguia como possível na ordem das condições (Vermögen) e o real na ordem do constituído (Erscheinung) é dado pela Antropologia numa continuidade indivisível" (FOUCAUL, M. "Introduction à l'Anthropologie", p.44).

17 HAN, B. L'ontologie manqué de Michel Foucault, p.58.

18 Essa questão se soma às outras três colocadas por Kant na "Doutrina Transcendental do Método": "que posso saber?", “que devo fazer?", “que é permitido esperar?". Na verdade, a questão "O que é o homem?", segundo Foucault, retoma e envolve todas as outras questões (Cf. FOUCAULT, M. "Introduction à l'Anthropologie", p.46).

19 FOUCAULT, M. “Introduction à l’Anthropologie”, p.47. 
campo da passividade originária. Em suma, vemos esboçar-se um domínio próprio da antropologia, aquele em que a unidade concreta das sínteses e da passividade, do afetado e do constituinte dá-se como fenômeno na forma do tempo ${ }^{20}$.

A fim de marcar a distância entre a antropologia kantiana e suas sucessoras que dormem no sono antropológico é preciso examinar em que sentido ela nos apresenta o transcendental e o empírico numa continuidade indivisível e em que sentido tal continuidade não coincide com a confusão entre empírico e transcendental. Aproximar a antropologia de Kant das antropologias ou analíticas da finitude que são, aos olhos de Foucault, uma falsa antropologia, seria mesmo um grande equívoco. Justifica o filósofo:

Haveria uma falsa antropologia - e a conhecemos demasiado bem: é aquela que tentaria deslocar em direção a um começo, em direção a um arcaísmo de fato ou de direito as estruturas do a priori. A Antropologia de Kant nos dá uma outra lição: repetir o a priori da Crítica no originário, isto é, em uma dimensão verdadeiramente temporal ${ }^{21}$.

Comecemos, assim, por compreender essa dimensão do originário que não pode se confundir com aquilo que é "realmente primitivo" ou arcaico, tal como pretendem as analíticas da finitude, mas deve ser entendido como o "verdadeiramente temporal".

Ao discorrer sobre os elementos da Crítica presentes na Antropologia, Foucault sugere que a segunda seria como uma espécie de negativo ou de inversão da primeira ${ }^{22}$. Isso seria observável, por exemplo, nas figuras da síntese e do dado. Diz Foucault:

(...) a relação do dado e do a priori assume na Antropologia uma estrutura inversa daquela que foi dada pela Crítica. $O$ a priori, na ordem do conhecimento, torna-se, na ordem da existência concreta, um originário que não é cronologicamente primeiro, mas que desde que aparece na sucessão nas figuras da síntese, se revela como um já aí; por outro lado, o que é o dado puro na ordem do conhecimento aparece, na reflexão sobre a existência concreta, com uma opacidade que the confere a profundidade do já operado ${ }^{23}$.

Por um lado, o originário não se confunde com o transcendental já que é da ordem do temporal; por outro lado, o originário também não se reduz ao domínio da multiplicidade empírica, uma vez que aparece na figura da síntese. De maneira análoga, o dado empírico, que numa investigação crítica acerca do conhecimento possível aparece como multiplicidade e dispersão, na Antropologia aparece como um

20 FOUCAULT, M. Gênese e estrutura na Antropologia de Kant. Tradução de Márcio Alves da Fonseca e Salma Tannus Michail. São Paulo: Loyola, 2011, p.33.

21 FOUCAULT, M. “Introduction à l'Anthropologie”, p.58.

22 Idem, p.41.

23 Idem, p.42. 
“já operado", isto é, como um "já sintetizado". Nem síntese pura do transcendental, nem multiplicidade dispersa do empírico. 0 originário, ao que tudo indica, é a efetividade da relação entre empírico e transcendental; é, pois, a região da experiência concreta; a região em que as condições de possibilidade transcendentais de uma experiência possível em geral já foram cumpridas, assim como foram cumpridas as condições empíricas particulares que possibilitaram a experiência que agora existe de fato.

Foucault parece apontar aqui para uma banalidade: o domínio do originário, que é por excelência a região da antropologia pragmática, é aquele onde as coisas acontecem de fato, onde a experiência aparece em sua efetividade concreta. E o que seria uma experiência enquanto efetividade concreta? Uma experiência que existe de fato e que cumpriu as duas condições necessárias para existir: foi realizada por um sujeito que garantiu sua unidade sintética da experiência, o sujeito puro, agente da síntese (condição transcendental) e foi experiência de uma multiplicidade empírica que deu o conteúdo da experiência (condição empírica).

Importantíssimo aqui é notar que o que está em questão é a ideia de que a distinção entre o nível transcendental e empírico da experiência é apenas uma distinção metodológica, que interessa apenas do ponto de vista do conhecimento, mas que não existe de fato no homem. Do mesmo modo que só existe de fato conhecimento que seja a união entre objetos empíricos a serem conhecidos e uma certa maneira subjetiva de conhecê-los, podemos dizer que o próprio homem só existe de fato como unidade concreta entre multiplicidade e síntese, passividade e atividade, determinação e liberdade. Não existe de fato concretamente um sujeito puro da síntese, de um lado, e a multiplicidade dos dados empíricos esperando serem sintetizados, de outro. Tal distinção só aparece quando decidimos fazer uma investigação crítica do mundo; fora dessa perspectiva um e outro domínio, o do transcendental e o do empírico, são inseparáveis. Sendo assim, o domínio do originário não é nem objeto de uma investigação puramente transcendental, como seria o caso da empreitada crítica, nem objeto de uma investigação absolutamente empírica.

E aqui vale retomar a diferença entre a "boa" e a "má" antropologia. Vimos acima que a boa antropologia, a antropologia pragmática de Kant, é aquela que repete o a priori da Crítica numa "dimensão verdadeiramente temporal". Isso quer dizer que a boa antropologia é aquela que é capaz de manter, no nível da descrição empírica do originário e do temporal, a distinção metodológica entre o que pode ser conhecido transcendentalmente e o que pode ser conhecido empiricamente, e não aquela que quer fazer valer o empírico como fundamental, transcendental ou atemporal.

Dizer que a Antropologia de um ponto de vista pragmático mantém a distinção 
metodológica entre transcendental e empírico significa dizer que ela não incorre nem no erro da ilusão transcendental, nem no erro da ilusão antropológica. E isso por uma simples razão: a antropologia pragmática de Kant, ao se restringir a uma observação empírica do homem, respeita os limites de nossa capacidade de conhecimento. Não procura descrever aquilo que está fora do alcance da experiência sensível, mas, ao contrário, descreve aquilo mesmo que é fruto desse tipo de observação: aquilo que os homens fazem realmente e a maneira como realmente se comportam, a maneira como "possuem o mundo"24.

Diz Foucault: “Coletânea de observações empíricas, a Antropologia não tem contato com uma reflexão sobre as condições da experiência"25. Mas aqui é preciso atenção. Não é porque a antropologia pragmática se limita a uma descrição daquilo que é observado empiricamente no homem que ela se confunde com uma ciência empírica. No prefácio da Antropologia de um ponto de vista pragmático, Kant alerta para a distinção entre uma antropologia do ponto de vista pragmático e uma do ponto de vista fisiológico:

Uma doutrina do conhecimento do ser humano sistematicamente composta (antropologia) pode ser tal do ponto de vista fisiológico ou pragmático. 0 conhecimento fisiológico do ser humano trata de investigar o que a natureza faz do homem; o pragmático, o que ele faz de si mesmo, ou pode e deve fazer como ser que age livremente ${ }^{26}$.

Central aqui é ressaltar o caráter pragmático da antropologia kantiana. Não se trata, para o filósofo alemão, de pensar o homem em sua empiricidade ou passividade de um ser determinado pela natureza, mas de pensá-lo como agente livre que age sobre esta natureza. Mas não nos enganemos mais uma vez! Já sabemos que o homem que a antropologia pragmática quer descrever também não pode coincidir com o sujeito puro de liberdade; se assim fosse, ela se confundiria com uma empreitada crítica. Assim, o sujeito que interessa conhecer, se não é o homo natura, tampouco é o sujeito puro pensado fora do tempo como condição de possibilidade para toda e qualquer ação livre; é um sujeito que age, de fato, livremente sobre si mesmo. 0 acento recai, portanto, na efetividade e não na possibilidade da ação livre, sobre o seu uso empírico e não sobre sua condição transcendental de possibilidade.

Ora, é a noção de uso (usage) que traduz do alemão Gebrauch que aponta para uma relação não contraditória entre empírico e transcendental. De acordo com Foucault, o domínio do originário da antropologia pragmática é aquele em que o homem faz uso concreto de suas condições transcendentais de possibilidade: é

24 Cf. KANT, I. Antropologia de um ponto de vista pragmático. Tradução de Célia Aparecida Martins. São Paulo: Iluminuras, 2006, p.23.

25 FOUCAULT, M. “Introduction à l'Anthropologie", p.41.

26 KANT, I. Antropologia de um ponto de vista pragmático, p.21. 
o domínio em que, de fato, o homem faz uso de suas faculdades mentais assim como de sua liberdade. Foucault nos fala em exercício cotidiano e em jogo a fim de explicar a ideia de uso. O filósofo nos lembra que, para Kant, o homem é um "jogo da natureza" ${ }^{27}$. Ou seja, é jogado pela natureza, no sentido que ela o determina: determina sua natureza e determina suas ações. Porém, insiste Foucault, o homem não é somente um jogo da natureza, mas ele mesmo, enquanto participa desse jogo, pode jogar com ela. Isso porque ele tem liberdade. Nesse sentido, diz Foucault, a Antropologia não é um livro de teoria, mas um livro sobre o exercício cotidiano, uma "análise da maneira como o homem adquire o mundo (seu uso, não seu conhecimento), quer dizer, como ele pode se instalar nele, e entrar no jogo" 28 .

Assim, se a Antropologia de um ponto de vista pragmático não deixa de ser uma espécie de repetição da Crítica é porque ao fazer uma descrição dos usos concretos que o homem faz de suas faculdades mentais e de sua liberdade, ela supõe que uma investigação crítica acerca dessas condições transcendentais já tenha sido realizada. Ou seja, ela supõe, no domínio do originário e do temporal, um “"já-aí”; um "já-ai” que diz respeito às condições transcendentais de possibilidades descobertas pela crítica. Dizer que a descrição dos usos concretos exige ou supõe uma investigação crítica acerca de suas condições de possibilidade, porém, não é a mesma coisa que dizer que a descrição empírica do modo como o homem habita o mundo tem validade de uma reflexão transcendental. Foucault insiste que a antropologia pragmática de Kant, apesar de ser uma repetição da Crítica, não se confunde com esta. E, no meu entender, é precisamente aqui que reside o interesse do filósofo por essa antropologia. A meu ver, a Antropologia de um ponto de vista pragmático pode ser dita uma "boa antropologia" justamente na medida em que é uma descrição empírica do homem no mundo que supõe uma fundamentação crítica, mas que não pretende, ela mesma, se configurar como tal.

Diferentemente do que sustenta Han, portanto, não acredito que a leitura que Foucaul fizera da Antropologia de um ponto de vista pragmático só tenha servido para indicar uma possível origem dos paradoxos presentes nas antropologias posteriores a Kant. No meu entender, Foucault teve um importante interesse teórico por esse texto de Kant. Nesse sentido, não é de se estranhar que em seu livro de método, $A$ arqueologia do saber, de 1969, por exemplo, a superação das analíticas da finitude ou das "falsas antropologias" será proposta justamente por meio de uma análise do discurso que não deixa de ser uma pesquisa sobre a facticidade da linguagem, isto é, sobre os usos concretos que os homens dão aos signos linguísticos, ao mesmo tempo que uma investigação crítica das práticas discursivas e não discursivas que possibilitaram a existência desses usos.

27 Cf. KANT, I. Antropologia de um ponto de vista pragmático, p.22.

28 FOUCAULT, M. “Introduction à l'Anthropologie”, p.33. 


\section{A filosofia crítica de Foucault e a recusa do transcendental: as condições de existência do enunciado não são condições transcendentais}

A ideia de que a arqueologia consiste numa investigação empírica acerca das "performances verbais" 29 indica que o interesse de Foucault é pelo o que os homens fazem no campo da linguagem, como eles a utilizam. Neste contexto, poderíamos dizer que o domínio de facticidade da linguagem que interessa a Foucault é chamado, por ele, de arquivo. Sendo que o arquivo é um conjunto de enunciados ou daquilo que foi efetivamente dito e escrito numa determinada época. Ou seja, na esteira da Antropologia de um ponto de vista pragmático, creio que podemos pensar o arquivo, em Foucault, como "coletânea de observações empíricas" acerca dos usos que os homens dão aos signos linguísticos.

Sabemos, no entanto, que a arqueologia de Foucault não se limita a localizar os enunciados em sua dispersão de acontecimento. É preciso, pois, como insiste o próprio filósofo, que a descrição empírica dos enunciados tenha como horizonte uma reflexão crítica acerca do que possibilitou a existência desses mesmos enunciados, o que possibilitou que uma coisa pudesse ter sido dita. Essa reflexão crítica que procura dar conta das condições que possibilitam o que é dito ou escrito numa determinada época, porém, não se confunde com a reflexão crítica kantiana. Desse modo, se por um lado dizemos que é possível aproximar o projeto filosófico de Foucault da antropologia pragmática de Kant, na medida em que nos dois casos trata-se de uma reflexão sobre aquilo que é da ordem do fato e do uso concreto, por outro lado a filosofia crítica pressuposta pela Antropologia de um ponto de vista pragmático não é a mesma que é pressuposta pela análise foucaultiana do discurso. Diria mesmo o contrário. A filosofia crítica de Foucault consiste numa inversão da filosofia crítica de Kant.

De acordo com Foucault, para compreender o que possibilita a existência de um enunciado, a efetividade de certo uso da linguagem, é preciso fazer uma investigação crítica em quatro dimensões diferentes: compreender o que possibilita a existência do objeto a que se refere o enunciado, a existência do sujeito que o enuncia, dos conceitos utilizados no enunciado e dos temas que ele envolve. É num texto escrito na década de 1980 para o Dicionário dos filósofos, de Huisman, que Foucault nos dá a melhor definição sobre o que significa investigar as condições de existência de um saber, ou, mais especificamente, de um enunciado. No que diz respeito às condições de existência do sujeito da enunciação, por exemplo, Foucault afirma: "a questão é determinar o que deve ser o sujeito, a que condição ele está submetido, qual estatuto ele deve ter, qual posição ele deve ocupar na

29 Cf. FOUCAULT, M. A arqueologia do saber. Tradução de Luiz Felipe Baeta Neves. Rio de Janeiro: Forense Universitária, 2007, p.121 e p.224. 
realidade ou no imaginário a fim de tornar-se sujeito legítimo deste ou daquele tipo de conhecimento" ${ }^{30}$. No que toca ao objeto de um enunciado, o filósofo esclarece: a arqueologia deve "determinar as condições em que alguma coisa pode tornar-se objeto para um conhecimento possível, como ela pôde ser problematizada como objeto a ser conhecido, a qual procedimento de recorte ela pôde ter sido submetida, a parte dela que foi considerada pertinente" ${ }^{31}$.

Em Foucault, as condições de possibilidade de existência de um enunciado, não estão, portanto, nem naquilo que o seu autor quis dizer como sujeito psicológico, nem num sujeito puro e transcendental que o possibilitaria. Confirma Foucault: "A linguagem, na instância de seu aparecimento e de seu modo de ser, é o enunciado; como tal, se apoia em uma descrição que não é nem transcendental, nem antropológica"32. A descrição que cabe dar ao enunciado é arqueológica. Nesse sentido, assegura Foucault, cabe ao arqueólogo "referir o discurso não ao pensamento e ao espírito do sujeito que the possibilitou o nascimento, mas ao campo prático no interior do qual ele se dá" ${ }^{33}$. Que campo prático é esse que interessa à reflexão crítica de Foucault? Aquele que envolve todas as operações discursivas ou não discurivas que estiveram envolvidas na constituição de certos tipos de objetos a serem enunciados, na constituição de certos sujeitos de enunciação, na constituição de certos conceitos e no desenvolvimento de certos temas. No verbete do Dicionário dos filósofos, em que apresenta sua própria obra a partir de um pseudônimo, Foucault, então, resume o sentido de sua filosofia crítica e as condições de possibilidades que o interessam investigar:

Se Foucault se inscreve numa tradição filosófica, é na tradição crítica que é aquela de Kant e poderíamos chamar essa empreitada de História crítica do pensamento. (...) uma histórica crítica do pensamento seria uma análise das condições nas quais são formadas ou modificadas certas relações entre sujeito e objeto, na medida em que estas são constitutivas de um saber possível. Não se trata de definir as condições formais de uma relação com o objeto (...) É preciso se desviar da démarche filosófica de voltar ao sujeito constituinte que esperamos dar conta daquilo que pode ser qualquer objeto de conhecimento em geral; trata-se ao contrário de descer na direção do estudo das práticas concretas por meio das quais o sujeito é constituido na imanência de um domínio de conhecimento. ${ }^{34}$

Assim, se, como vimos, a antropologia pragmática de Kant não deixa de ser uma repetição da Crítica, uma vez que a descrição empírica dos usos concretos das faculdades da mente pressupõe suas condições transcendentais de possibilidade, assim como da liberdade transcendental, a arqueologia de Foucault, que descreve os

30 FOUCAULT, M. “Foucault”. In: Dits et écrits vol. II. Paris: Gallimard, 2001, p.1451.

31 Idem, ibidem.

32 Cf. FOUCAULT, M. A arqueologia do saber, p.128.

33 FOUCAULT, M. Réponse à une question, p.711.

34 FOUCAULT, M. “Foucault”. In: Dits et écrits vol. II, pp.1451-1453. 
usos da linguagem (o que foi, de fato, dito), também não existe sem uma referência às condições de possibilidade desses usos. Porém, se é verdade que, em Foucault, assim como em Kant, é imprescindível que o conhecimento pragmático dos usos pressuponha uma investigação acerca das “condições de possibilidade”, é só num sentido aproximativo e relativo que as condições de existência dos enunciados, em Foucault, podem ser entendidas como transcendentais.

É verdade que, se entendermos o transcendental, em Kant, como um tipo de reflexão que se pergunta pelas condições de possibilidade (do conhecimento, da ação moral ou do juízo), podemos dizer, sim, que há em Foucault uma éspecie de reflexão transcendental. O esforço da arqueologia e da genealogia parece ser justamente o de compreender as condições de possibilidade de certos saberes. Por outro lado, se levarmos em conta que as condições de possibilidade, em Kant, são sempre condições subjetivas e universais, ou seja, remetem sempre a um sujeito transcendental, aí, então, é preciso dizer que a filosofia crítica de Foucault não é transcendental. Afinal, em Foucault, as condições que possibilitam que algo seja dito ou escrito numa determinada época não são nem da ordem do subjetivo, muito menos da ordem do universal. Elas são, ao contrário, exteriores ao próprio sujeito e dizem respeito a uma série de práticas ou operações históricas que não funcionam como condiçõos formais e universais de validade, mas como condições concretas e singulares de realidade.

Entretanto se, por um lado, a investigação crítica de Foucault se afasta da reflexão kantiana do transcendental, por outro lado, não me parece que ela seja completamente estranha ao pensamento de Kant. Vale lembrar, por exemplo, que no famoso artigo “Resposta à pergunta: 'O que é Esclarecimento?”, Kant deixa claro, e esse ponto é ressaltado por Foucault em suas diversas leituras do texto kantiano, que o uso público da razão não depende somente da condição transcendental, subjetiva e universal, da liberdade, mas sobretudo de condições concretas ou históricas que possibilitem a liberdade transcendental existir de fato (Kant insiste, por exemplo, como se sabe, que era condição para o Esclarecimento e, portanto, para o uso público da razão, um governante esclarecido que possibilitasse, concretamente, a liberdade de pensamento nesse domínio). A liberdade transcendental, portanto, é condição necessária, mas não suficiente para a efetividade do uso público da razão. De acordo com esse texto de Kant, para se pensar livremente, e caminhar no sentido do Esclarecimento não basta ser, por direito, um sujeito livre, mas é preciso encontrar condições concretas de liberdade que possibilitem, de fato, o uso ou o exercício da liberdade transcendental. Com outras palavras: para que as condições transcendentais sejam de fato usadas, é preciso certas condições concretas que possibilitem a existência do uso. Ora, no meu entender, é exatamente por esse caminho que segue a investigação crítica de Foucault. E se, em Kant, a Antropologia 
de um ponto de vista pragmático aponta para os usos concretos que damos a nossas condições transcendentais de possibilidades, é o texto sobre o Esclarecimento que chama atenção para as condições concretas desses usos. Nesse sentido, temos aqui uma possível justificativa para o fato de Foucault, depois da tese complementar, não ter mais se referido à antropologia pragmática kantiana, mas, por outro lado, ter retomado o texto sobre o Esclarecimento como paradigma para uma reflexão crítica sobre nossa situação no mundo. Se a investigação crítica exigida pela antropologia pragmática ainda era uma investigação crítica acerca do sujeito transcendental, é no texto sobre o Esclarecimento que vemos entrar em cena um outro tipo de reflexão crítica: aquela que se pergunta pelas condições concretas e históricas que possibilitam que algo, de fato, exista. Outro tipo de reflexão crítica que, com as palavras de Foucault, não se perguntaria mais por um a priori formal, mas por um $a$ priori histórico ${ }^{35}$.

Para concluir, então, retomo uma passagem de $A$ arqueologia do saber em que Foucault explica em que sentido o a priori histórico investigado por ele se diferencia do a priori formal ou transcendental; uma passagem que parece se aproximar do que dissemos acima sobre as condições concretas de liberdade abordadas por Kant no texto sobre o Esclarecimento:

Diante dos a priori formais cuja jurisdição se estende sem contingência, ele [o a priori histórico] é uma figura puramente empírica (...) Ele não pode dar conta dos a priori formais; mas permite compreender como os a priori formais podem ter na história pontos de junção, lugares de inserção, de irrupção ou de emergência, domínios ou ocasiões de utilização (...) O a priori formal e o a priori histórico não são nem do mesmo nível nem da mesma natureza: se se cruzam é porque ocupam duas dimensões diferentes ${ }^{36}$.

\section{Referências}

FOUCAULT, M. Dits et écrits vol.l e II. Paris: Gallimard, 2001. As palavras e as coisas. Tradução de Salma Tannus Muchail. São Paulo: Martins Fontes, 2002. A arqueologia do saber. Tradução de Luiz Felipe Baeta Neves. Rio de Janeiro: Forense Universitária, 2007.

35 Vale notar que, ao distinguir a priori formal e a priori histórico ou condições de possibilidades transcendentais e condições de possibilidades históricas, Foucault não pretende negar a existência dos primeiros termos da comparação. Sua intenção é, antes, a de colocar em suspenso essa dimensão a fim de deter-se mais cuidadosamente sobre a dimensão histórica e empírica. É o que o filósofo deixa claro em entrevista de 1972: "Ao longo de toda minha pesquisa, esforcei-me para evitar toda referência a esse transcendental que seria uma condição de possibilidade para todo conhecimento. Quando eu digo que me esforço para evitar, não afirmo que tenho certeza de tê-lo conseguido. (...) Tento historicizar o máximo para deixar o mínimo de lugar possível ao transcendental. Não posso eliminar a possibilidade de me encontrar, um dia, diante de um resíduo não neglicenciável que seria o transcendental" (FOUCAULT, M. "Les probémes de la culture. Un débat Foucault-Preti". In: Dits et écrits vol. I, p.1241).

36 FOUCAULT, M. A arqueologia do saber, pp.145-6. 
. “Introduction à l'Anthropologie". In: KANT, I. Anthropologie d'un point de vue pragmatique. Paris: Vrin, 2008. (Gênese e estrutura da Antropologia de Kant. Tradução de Márcio Alves da Fonseca e Salma Tannus Michail. São Paulo: Loyola, 2011).

HAN, B. L'ontologie manqué de Michel Foucault. Grenoble: Millon, 1998.

HÖFFE, O. Immanuel Kant. Tradução de Christian Viktor Hamm e Valerio Rohden. São Paulo: Martins Fontes, 2005.

KANT, I. Antropologia de um ponto de vista pragmático. Tradução de Célia Aparecida Martins. São Paulo: Iluminuras, 2006.

- Crítica da Razão Pura. Tradução de Manuela Pinto dos Santos e Alexandre Fradique Morujão. Lisboa: Fundação Calouste Gulbenkian, 2001.

LEBRUN, G. “Transgredir a finitude”. In: RIBEIRO, R. (org.). Recordar Foucault. São Paulo: Brasiliense, 1985.

VUILLEMIN, J. L'Héritage kantien et la révolution copernicienne: Fichte - Cohen Heidegger. Paris: PUF, 1954. 